\title{
Psychotherapy. Non-pharmacological treatment
}

\section{GROUP-ORIENTED APPROACHES IN THE THERAPEUTIC COMMUNITY OF THE DAY HOSPITAL. \\ J.Mantonakis, E.Gyra, K.Katan, K. Theohari, C.Stefanis Athens University Medical School, Psychiatry Department, Eginition Hospital, 72-74 Vas.Sophias Ave., 11528 Athens Grecce}

The Therapeutic Community of the Day Hospital is a dynamic combination of psychotherapeutic, sociotherapcutic and biological approaches. Whithin this framework an "cgo training in action" is pursued through the group dynamics. Since our model is primarily group-centered, the philosophy, as well as the goals of the groups involved within the therapeutic program, will be presented.

I. Groups based mainly on the psychodynamic approach:

a) Group psychotherapy on a daily basis

b) Art therapy

c) Drama therapy

II. Large group of the therapcutic community (self-administration)

III. Sociotherapeutically-oriented groups:

a) Group activities focused on learning and development of specific skills: (1) ergothcrapy, (2) social skills group, (3) body care group, (4) first aid, medical education group

b) Social activities : (1) theatrical performances, (2) farewell parties, (3) visits to cultural centers (galleries, museums etc), (4) excursions, (5) season bazzars

c) Groups focused on the therapcutic use of play, mythology, proverbs etc.

IV. Groups focuscd on the "somatic cgo": (1) relaxation group, (2) Herapeutic gynuastics group. (3) music, novement and dance group

V. Follow-up group

VI. Staff activilics: (1) sensitivity group. (2) clinical meetings (inscrvice training). (3) supcrvision (gtoup psychothcrapy. fanily (herapy cle)
FAMILY INVOLVEMENT IN TREATMENT PROCESS

\begin{abstract}
A. Nikolova
Daily Centre for habilitation of autistic children, Boyana, 112 Detska Gradina, 5 Detsky mir str., Sofia, Bulgaria

According to our understanding for the different forms of interventions in child psychiatric disorders, since 1988, we have developed a TFFIProgramme (three focal forms of interventions) for habilitation of autistic children. The focuses are as follows: the child, the family and the society. The programme emphasises on the actively involvement of the family in the educational and behavioral treatment of the autistic children. We train the parents as co-therapists modelling the different parent-professional relationships, which includes: the traditional roles, inversion of the traditional roles, mutual emotional support and social advocacy - for looking after human and civil rights of autistic individuals.

There are different forms of family training, including so called Sunday School for parents, Summer School for autistic children and their parents.
\end{abstract}


NON-PHARMACOLOGICAL PROPHYLAXIS INAFFECTIVEDISORDERS GN Papadimitriou, GN Chiristodoulou, YG Papakostas, CN Stefanis Department of Psychiatry, Athens University, Eginition Hospital, 74 Vas. Sophias Ave., Athens 11528, Greece

Prophylaxis is a very important issue in affective disorders, since relapse and recurrence are common complications in the course of the illness. Often, pharmacotherapy does not provide optimal prophylaxis. To evaluate the efficacy and safety of non-pharmacological treatments, ECT and sleep deprivation (SD) were administered prophylactically. Unilateral modified ECT was given to eight female depressed (DSM-III-R) outpatients (age range 20 to 72 years), initially twice and afterwards once a month for a period of 2 to 51 months. Seven patients remained normothymic during the intervention period. No significant side effects occurred. Total SD was applied, once a week, in six drug-free depressed outpatients $\mathrm{k}$ ( 1 male, 5 female, age range 29 to 52 years). Four of them, all rapid cyclers, had an excellent response. These observations suggest that continuation and maintenance unilateral ECT and total SD are appropriate and efficient alternatives to the pharmacological prophylaxis of affective disorders.

\section{PSYCHOLOGICAL TREATMENT OF PANIC ATTACKS}

A. Püras, R. Sersknienè, D. Deltuvienè

Psychiatry Clinic of Kaunas Medical Academy, Eivieniu 2, 3000 Kaunas, Lithuania

Until now the main treatment of panic attacks was pharmacotherapy. But already we can find in literature articles on comparison of psychological treatment of panic attacks and other methods of treatment.

Our investigations were based on three methods, suggested by R. Rapel and D. Barlow. They are: relaxation and breathing control, cognitive change and interoreceptive exposition. Our work was based on the analysis of 37 patients with panic attacks, to whom those methods were used for treatment. In our work we were using all three methods, trying to make the treatment more effective. The treatment of the patients began from the information and cognitive change, later continuing treatment we taught the patients breathing control and exposition exercises. In most of the cases all three of these components supplemented each other. Combining all three components, an effective model of treatment was created. We examined those patients half a year after the course of treatment. For $25(67,6 \%)$ patients panic attacks did not take place. For $6(16,7 \%)$ patients the frequency of the attacks decreased significantly. For $6(16,7 \%)$ patients there was no effect from the treatment.

The conclusion is that the psychological treatment of panic attacks is effective. It can be an alternative for the treatment with medications, often used as the only one method of treatment of panic attacks. Such psychological treatment of panic attacks is an urgent problem in post-soviet countries, as we now lack medication.

\section{FAMILY INTERVENTIONS DURING BRIEF PSYCHIATRIC HOSPITALISATION}

\section{V.Tomaras, P.Oulis, N.Papavasiliou}

Athens University Medical School, Department of Psychiatry, Aeginition Hospital, 74 Vas.Sofias Ave, Athens 11528 Greece

Family interventions have been largely used in the treatment of psychiatric inpatients and outpatients Certain modes of intervention have been applied into controlled clinical trials, and have, more or less, proved their effectiveness, some others not.

The techniques to be described here have been introduced as an adjunct to the routine treatment in an acute, 10 bed, ward of a psychiatric hospital. Their aim is three fold: (a) to shorten current hospitalisation, (b) to reduce the neuroleptic dosage, especially in cases of excessive side-effects or non responsiveness, and (c) to prevent relapse at least in the short run.

Issues concerning the methodology and limitations of this brief intervention will be discussed; a case vignette will illustrate the conceptual and practical aspects of the presentation. 